Portland State University

PDXScholar

6-14-1985

\title{
A Comparison of the Effects of EMG Biofeedback and Relaxation Training on Chronic Back Pain Patients
}

Pam W. Vredevelt

Portland State University

Follow this and additional works at: https://pdxscholar.library.pdx.edu/open_access_etds

Part of the Biological Psychology Commons

Let us know how access to this document benefits you.

Recommended Citation

Vredevelt, Pam W., "A Comparison of the Effects of EMG Biofeedback and Relaxation Training on Chronic Back Pain Patients" (1985). Dissertations and Theses. Paper 3539.

https://doi.org/10.15760/etd.5423

This Thesis is brought to you for free and open access. It has been accepted for inclusion in Dissertations and Theses by an authorized administrator of PDXScholar. Please contact us if we can make this document more accessible: pdxscholar@pdx.edu. 
AN ABSTRACT OF THE THESIS OF Pam W. Vredevelt for the Master of Science in Psychology presented June 14, 1985 .

Title: A Comparison of the Effects of EMG Biofeedback and Relaxation Training on Chronic Back Pain Patients.

APPROVED BY MEMBERS OF THE THESIS COMMITTEE:
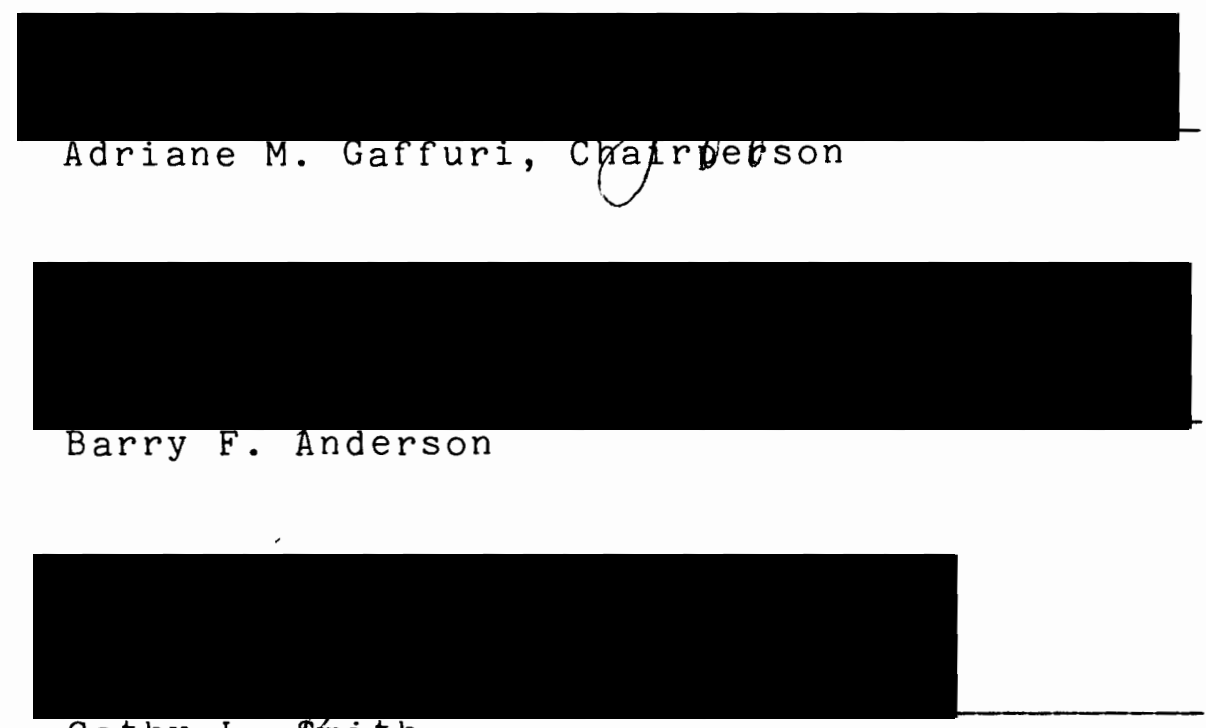

Cathy L. Smith

This experiment examined the effects of EMG biofeedback and relaxation training as compared with biofeedback alone. The following dependent variables were examined: manifest anxiety, perceived pain, perceived relaxation, EMG activity, and locus of control. Back pain patients were assigned to one of two treatment groups. Group 1 was treated 
with both EMG biofeedback and relaxation training. Group 2 was treated with biofeedback alone. It appears that both biofeedback combined with progressive relaxation and biofeedback training alone are effective in lowering muscle activity and perceived pain, and in increasing perceived relaxation. However, from the results of this study, it is impossible to conclude that one treatment method is more effective than the other. Suggestions for future research are discussed. 


\title{
A COMPARISON OF THE EFFECTS OF EMG BIOFEEDBACK AND RELAXATION TRAINING ON CHRONIC BACK PAIN PATIENTS
}

by

PAM W. VREDEVELT

A thesis submitted in partial fulfillment of the requirements for the degree of

\author{
MASTER OF SCIENCE \\ in \\ PSYCHOLOGY
}

Portland State University

1985 
TO THE OFFICE OF GRADUATE STUDIES AND RESEARCH

The members of the Committee approve the thesis of

Pam W. Vredevelt presented June 14, 1985.

Adriane M. Gaffuri, ChAlitplerson

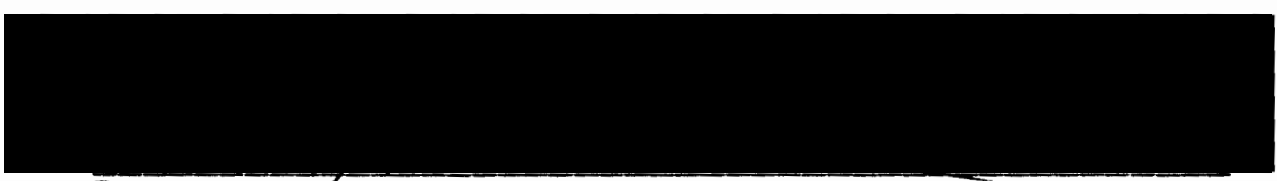

Barry F. Anderson

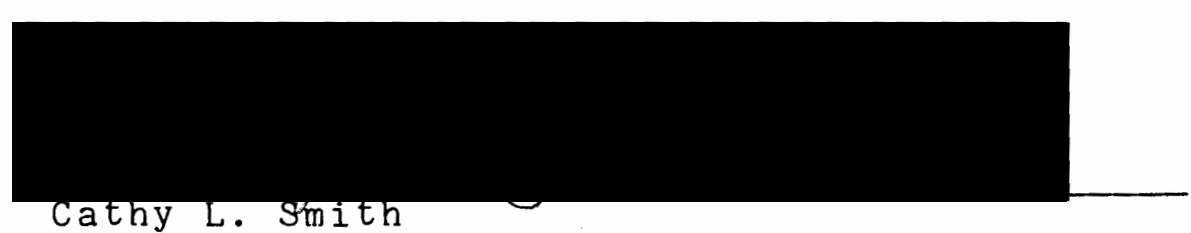

APRROVED:

Rogef Jénnjugs fread, Departpent of Psychology

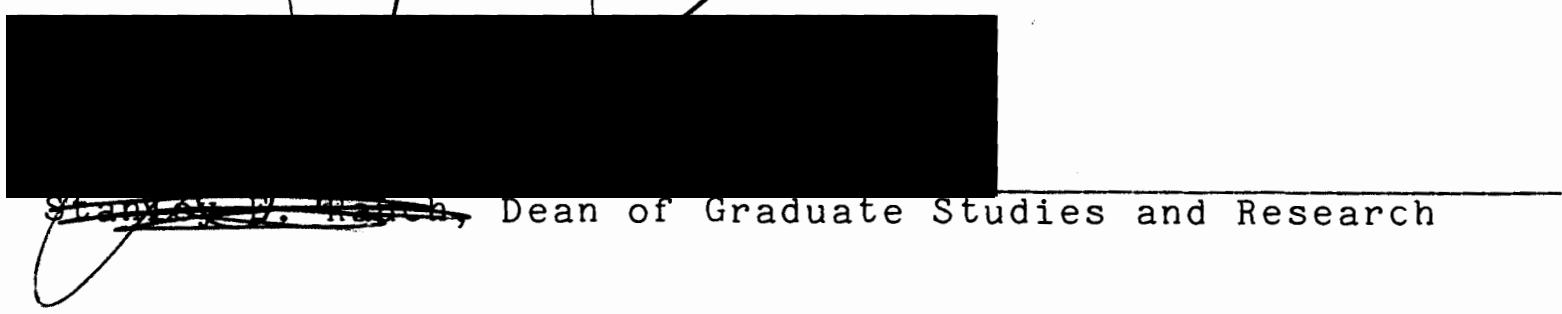




\section{ACKNOWLEDGMENTS}

The author would like to express her appreciation to the faculty of the Department of Psychology who gave their time and counsel to this study. A special thanks is due the following: to her thesis advisor, Dr. Adriane Gaffuri, for her genuine and enthusiastic support, sound advice, and helpful assistance; to the members of her committee, Dr. Barry Anderson and Dr. Cathy Smith, for their insightful comments and constructive ideas; to Dr. Donald Howard, for his generous assistance in the statistical analysis of the data.

The author would also like to express her thanks to Betty Guse, who skillfully and diligently typed this thesis. Deep gratitude is due my husband, John, whose devotion and loving support has encouraged me to complete this project. 
TABLE OF CONTENTS

PAGE

ACKNOWLEDGMENTS . . . . . . . . . . . . . . . . . .

LIST OF TABLES . . . . . . . . . . . . . . . . vi vi

CHAPTER

I INTRODUCTION . . . . . . . . . . . . . . 1

The Problem of Pain........ 1

Theoretical Models for the

Perception of Pain . . . . . .

2

A Review of the Literature

Concerning EMG Biofeedback

And Muscle Relaxation

Treatment of Chronic Back

Pain........... 10

A Review of the Literature

Concerning Anxiety,

Muscle Tension and Pain.....

A Review of the Literature

Concerning Locus of Control

in Relation to Biofeedback

And Pain . . . . . . . . . 19

Statement of the Problem. . . . . 21

Purpose of the Study ....... . 22

Research Hypotheses........ . 23

II METHODS . . . . . . . . . . . . . 26

Subjects . . . . . . . . . . 26

Apparatus and Materials . . . . . 27 
The Manifest Anxiety Scale. . . 28

Perceived Pain/Perceived

Relaxation Scale. . . . . . . . 29

Locus of Control Scale:... . . 29

Prodedure . . . . . . . . . . . 30

III RESULTS • . . . . . . . • . . . . . . 33

EMG Activity . . . . . . . . . 33

Perceived Pain/Perceived Relaxation. - 34

Locus of Control . . . . . . . 36

Manifest Anxiety . . . . . . . . 37

IV DISCUSSION • . . . . . . . . . . . . . 38

Limitations of the Study . . . . . . 43

Suggestions for Future Research . . . 43

REFERENCES • • • • • • • • • • • • • • • • • • • • • 45

APPENDIX

A Informed Consent Form. . . . . . . . 50

B Jacobson's Progressive Relaxation

Technique . . . . . . . . . . 52

C Taylor's Manifest Anxiety Scale . . . . . 60

D Perceived Pain and Perceived

Relaxation Scale... . . . . . 63

E Locus of Control Scale... . . . . . . 65

F Raw Data and Analysis of Variance

Summary Tables.. . . . . . . 69 


\section{LIST OF TABLES}

TABLE

P.AGE

I EMG Levels Pretraining and Posttraining . . . 70

I Perceived Pain Scale Scores Pretraining And Posttraining . . . . . . . . . 71

II Perceived Relaxation Scale Scores

Pretest/Posttest . . . . . . . 72

IV Locus of Control Scores Pretraining And Posttraining . . . . . . . . . 73

$V$ Manifest Anxiety Scale Scores Pretraining And Posttraining . . . . . . . . . 74 
CHAPTER I

INTRODUCTION

The Problem of Pain

Chronic pain is a major national medical problem. Treatments for chronic pain represent a major portion of medical costs nationally. Costs include payments for hospitalization and outpatient treatments, workmen's compensa(tion tion and disability payments, and time lost from work. These costs are staggering and growing rapidly.

Chronic pain is defined as pain of at least 6 months' duration that is nonmalignant in etiology. Patients suffering from chronically painful conditions often develop behavioral and psychological problems (Keefe, 1982). These include a sedentary lifestyle with a very limited range of activities, excessive dependence on spouse and family, narcotic addiction, anxiety, depression, and hypochrondriasis. Chronic pain patients have been described as failures of traditional medical and surgical treatment (Urban, 1982). Most patients have undergone extensive treatment aimed at removing underlying somatic pathology that may be responsible for their pain. In most cases, further medical and surgical intervention is ruled out either because these treatments would have negative effects 
or because they are unlikely to help (Urban, 1982).

There is growing recognition of the importance of behavioral and psychological factors in the maintenance of chronic pain (Keefe, 1982). Primary-care physicians as well as medical and surgical specialists are beginning to incorporate psychological and behavioral techniques as a routine part of assessment and management of chronic pain patients. Specialized behavioral treatment programs also have been developed to treat chronic pain. While these programs use a variety of treatment methods, almost all have a biofeedback component.

\section{Theoretical Models for the Perception of Pain}

Due to the recognition of the important role that psychological processes play in the human experience of pain, there has been a significant increase, in recent years, in participation by psychologists in pain treatment and pain research. However, overall there have been very few attempts to extend theory and principles from the field of psychology to the study of pain. One possible explanation for this is that the prevailing theory guiding pain investigation for almost 100 years was that pain was primarily a sensory phenomenon and as such could only be properly studied in biological and physiological laboratories (Bonica, 1980; Melzach, 1980).

There are several theories of pain, but no single theory can account for all pain phenomena. After many years of physiological research on sensation, three con- 
flicting theories of pain existed at the end of the 19th century (Bonica, 1980). The specificity theory maintained that pain is a specific sensation, independent from other senses. The intensive theory stated that every sensory stimulus was potentially pain producing if it exceeded a certain threshold for intensity. The third theory was a variation of intensive theory known as the pattern theory, where pain was understood as a resultant of the summation of a spatial and temporal pattern of input. According to pattern theory there are no pain endings, pain fibers, or pain neurons in the peripheral nervous system (Crue and Carregal, 1975).

A more modern variant of the intensive and pattern theories, the gate control theory, was developed by Melzach and Wall (1965). This theory attempts to account for psychological influences on pain perception, as well as the spread of pain and persistance of pain after tissue healing. This theory proposes a dorsal spinal gating mechanism in the subtantia gelatinosa of the spinal cord that modulates sensory input by the balance of impulses arriving in large afferent fibers (A-beta) and small afferent fibers (A-delta and C fibers). Activity of large fibers closes the gate and prevents synaptic transmission to centrally projecting transmission cells, thereby inhibiting the perception of pain. Small fibers open the gate to facilitate transmission cell activity once a critical level is reached, resulting in the perception of pain. Small fiber activity 
is thought to be responsible for the prolongation of pain and its spread to other parts of the body (Melzach, 1973). A central control trigger can also influence the gate. Thus, cognitive processes can either open or close the gate, which could account for the many successes of biofeedback in treating psychosomatic pain (Weisenberg, 1977).

Convincing evidence for some aspects of the gate theory can be found in the fact that large fibers inhibit pain transmission; however, there is considerable controversy as to the validity of the gate control theory at present. Fisher-Williams, Nigl, and Sovine (1981) argue against its validity on two major points: first, dorsal horn cells have been identified that respond selectively to noxious stimuli, and second, natural stimulation of small afferent fibers resulted in negative, not positive, dorsal root potentials.

Although contradictory evidence has recently accumulated questioning the gating hypothesis, the significance of the theory cannot be overemphasized. According to Bonica (1980), this theory helped reintroduce the importance of the psychological and physiological aspects of pain, and created an upsurge of research on pain perception. Another theory that has emphasized the importance of both the psychological and physiological aspects of pain is presented by Chapman (1980). Chapman (1980) makes one of the most recent and most comprehensive attempts to relate the clinical experience of pain to various concepts 
in psychology. Given the dearth of work in this area, Chapman:s (1980) theory on pain perception stands alone from other theories in that it can be used as a model for studying pain within the context of perceptual psychology ( Nigl, 1984).

According to Chapman (1980), pain is an extremely complex phenomenon which is more than just a sensory experience brought about by the combination of peripheral receptors and spinal pain pathways. He emphasized that there is ample evidence that emotions, cognitive factors, and personality interact with sensory activities to create the subjective human experience referred to as pain.

With respect to various concepts of perceptual psychology, Chapman (1980) divided his model into 2 basic areas: attention (the process of selecting and integrating sensory inputs) and central processing (the process of centrally organizing the sensory information that has been selected and integrated). The attention system is activated whenever a person suffers an injury. Information about that injury supersedes all other somatic sensations. Through this system the brain acquires many types of data regarding the extent of injury, or the severity, and the type of behavioral response needed to protect the body from further harm (Chapman, 1980).

Certain persons have a tendency to react to a particular class of stimuli, even though the signals are weak or rarely present. This attentional predisposition is re- 
ferred to as vigilance (Mackworth, 1950). It frequently develops as a result of reinforcement a person may have received for selectively attending to a certain type of information. For example, chronic pain patients of ten have been differentially reinforced by significant others for reporting pain and related symptoms (e.g., immobility, fatigue). Thus, many chronic pain patients have developed vigilance habits for pain sensation, even if the pain signals are weak or infrequent. Whenever the feeling of pain occurs, there is an interaction between perception and cognition at some level. Beliefs, attitudes, and expectations influence the perception of pain (Nigl, 1984).

Chapman indicated that noxious information is frequently ambiguous and, therefore, subject to cognitive processing or classification. This process may reduce the pain sensation (e.g., when an athlete shrugs of $\mathrm{f}$ a minor injury during an athletic contestl or it may amplify the pain and heighten anxiety (e.g., when a patient with cardiac neurosis experiences chest pain of even minor intensity).

In discussing central processing, Chapman (1980) attempted to synthesize common concepts among the major theories of perception (e.g., Gestalt, information, and signal detection theoryl as they relate to pain perception. Several of these concepts are worth mentioning. One of the concepts is figure-ground, which was developed by Gestalt psychologists (Avant and Helson, 1973). 
This has also been called signal noise (signal-detection theory) and information uncertainty (information processing theory). An individual continually scans his perceptual field during the waking state. This field consists of all sources of information available to the individual. Based on the figure-ground hypothesis, persons process only relevant information and ignore the rest of the perceptual field. Chapman (1980) states that stimulus relevancy is determined by three factors: 1) immediate needs, 2) future goals, and 3) indications of threat or physical harm. Figure-ground phenomena occur when one set of stimuli suddenly becomes paramount while other possible sets of sensory information fade into the background.

It is possible to consider biofeedback in relation to this figure-ground phenomena. As a patient is trained in biofeedback, he is learning the skill of self-regulation. In other words, while working with an EMG machine, the patient is forced to organize new sensory information that has been selected and integrated. Concerning Chapman's (1980) remarks about stimulus relevancy, if a patient feels the need to gain control over muscle tension in order to reduce pain, and pain management or pain reduction is a future goal, then the biofeedback stimulus he is attending to is, indeed, relevant. This may account for the fact that at the end of some biofeedback sessions, patients report a decrease in perceived pain. Perhaps the biofeedback stimulus became paramount during the training session, thus forcing other sensory (pain) information to fade into the 
background of the patient's perception.

Another important concept is perceptual stability.

One of the major characteristics of human perception is the tendency to maintain relatively stable patterns even when some discuption has occurred in the sensory information. According to Chapman $(1980)$, this tendency is referred to as constancy. It protects the "integrity" of perceptual configurations or, to use Gestalt terminology, wholes. Perceptual psychologists have found that it is easier for the human organism to perceive a configuration or whole than it is to perceive the component parts. Pattern recognition research has demonstrated that removing parts of a whole pattern does not significantly alter the perception of the pattern (Nigl, 1984). For example, Chapman (1980) indicated that transforming a circle into a curved line of dots will not change the perception of the circle shape. This particular perceptual phenomenon is called closure. How do these concepts from psychology relate to human pain perception? Chapman (1980) indicates that many chronic pain patients suffer from "excessive stability of perceptual organization." In effect, what this means is that they suffer pain even though the pain perception signals have been removed (e.g., through analegesic nerve blocks). This phenomenon occurs because pain is a perceptual whole that is perceived, based on the principle of closure and constancy, even though a part has been removed (the perception of pain). Using such principles, one can account for the severe pain frequently exhibited by patients in the absence 
of organic disease, trauma, or malingering. Often times chronic pain patients, especially back pain patients, have pain years after successfully undergoing surgery to correct the orthopedic problem that led to the pain in the first place (Nigl, 1984).

It is a worthwhile venture to consider how biofeedback training could be beneficial to the pain patient who exhibits an excessive stability of perceptual organization. The biofeedback information can act as a consistent "disrupter" of the stable patterns or the "wholes" that the patient normally perceives. Theoretically, the pain patient can learn to reorganize his perceptual field according to the feedback received in training. Over time, the patient can begin to control the physiological activity that has been fed back to him by utilizing internal cues or references which correlate with positive changes in the bioelectric signals. As the patient attends to and integrates this new form of sensory information on a consistent basis, it seems safe to assume that his perceptual "wholes" would gradually be altered, thus allowing for a new or reorganized perception of his pain.

More than any of the other theoretical approaches, Chapman's (1980) model of pain perception emphasizes the tremendous role of psychological variables and how they may affect a person's perception of pain. Within Chapman's (1980) construct, behavioral approaches such as biofeedback and progressive relaxation should be considered as useful and important methods for helping patients who suffer with 
chronic pain.

A Review of The Literature

Concerning EMG Biofeedback And Muscle Relaxation Treatment of Chronic Back Pain

One of the first published reports of the use of biofeedback for chronic back pain treatment was presented by Kravitz, Moore, Glaros, and Stauffer (1978). These researchers described an EMG biofeedback treatment program with 14 chronic back pain patients. Differential relaxation training was conducted with subjects trying to contract and relax various muscle groups while at the same time attempting to keep their paralumbar muscles relaxed with EMG feedback. Significant reductions in EMG activity occurred during these tension exercises at the posttraining period; 69 percent of all patients tested reported experiencing some lessening of back discomfort. The group that received relaxation plus biofeedback, however, did not have significantly better results than the group that received relaxation alone. Biofeedback did not appear to add anything to the effect of relaxation used by itself. This may have been due, however, to the low number of EMG training sessions (five).

Freeman, Calsyn, and Louks (1976) evaluated the effectiveness of an EMG biofeedback program with eight chronic back pain patients. Four of the eight patients reported having less pain after biofeedback. The other four became worse or remained the same. Personality testing was not found to be helpful in predicting those who would improve 
and those who would stay the same or worsen. However, the five subjects who showed the greatest behavioral improvement had scale 2 (Depression) elevations as high or higher than scales 1 (Hypochondriasis) and 3 (Hysteria). Overall, these results seem to be somewhat inconclusive in regard to efficacy of EMG biofeedback training for back pain (Nigl, $1984)$

Todd and Belar (1980) reported on a single case in which EMG biofeedback did not lead to improved functioning. The patient received progressive relaxation training and EMG biofeedback training. It appears that the patient's degenerative disc disease contributed to his inability to benefit from EMG biofeedback training. The authors concluded that biofeedback may not be a treatment of choice for everyone and that the existence of progressive organic disease be ruled out before making referral for biofeedback therapy.

In contrast to Todd and Belar's (1980) negative findings, Nouwen and Solinger (1979) found significant improvement in a group of 19 back pain patients receiving biofeedback when compared to a control group of patients who did not receive any treatment. A follow-up study conducted three months after the treatment ended showed the group that received EMG biofeedback training exhibited EMG levels similar to baseline but reported lower levels of pain.

Thus, although the subjects did not appear to learn to control their muscle tension, the biofeedback aided in decreasing their subjective experience of pain. The authors evaluated individual responses to the treatment and found 
that a certain group of patients who made substantial reductions in EMG levels during the biofeedback training also reported significant decreases in pain and had very low levels of pain after the three-month follow-up period (Nigl, 1984). Nouwen and Solinger (1979) suggested that a feeling of selfcontrol was responsible for these reductions in pain. It appears that biofeedback training helped improve the patients' cognitive experience of pain, even though it didn't appear to influence muscle contraction levels.

Another study by Nigl (1980) investigated the effectiveness of EMG feedback combined with focused imagery relaxation compared with the relaxation technique used alone. Seven patients with posttraumatic back pain (including four who suffered work injuries, two who suffered automobile injuries and one who suffered a gunshot wound) served as their own controls. During phase one of the study all subjects received the relaxation techniques alone. During phase two, they received a combination of the relaxation-biofeedback techniques. The results indicate that pain ratings and EMG paraspinal activity were significantly lower during the EMG feedback sessions compared with sessions without feedback. These results suggest that the EMG feedback helped the patients lower their muscle tension beyond what was possible with an imagery/relaxation technique (Nigl, 1984).

Fisher-Williams, Nigl, and Sovine (1981) used EMG biofeed combined with relaxation training to treat several cases of chronic back pain. These investigators found that 
four patients with chronic back pain improved significantly as a result of EMG biofeedback training oriented toward teaching them to relax excessive muscular contractions while in a resting position. The results of their combined EMG biofeedback and focused imagery relaxation training showed a significant reduction in muscle functioning. The investigators concluded that although there were many factors present which increased the probability of unsuccessful results, the objective information which the patients received about their paraspinal muscle functioning appeared to increase their motivation to learn control of this activity. In addition, the patients' self-esteem seemed to improve as a result of their achieving control over their muscle contraction and concomitant pain. Although all of these patients were out of work at the time of biofeedback treatment, all obtained employment or entered vocational training after completion of the program.

Several studies in the literature have combined relaxation training and biofeedback for the treatment of chronic pain, as shown above. Seer (1979) reviewed 20 studies comparing biofeedback, relaxation and meditation training. Seer felt that these studies comparing the three therapies were inconclusive. He suggested that the relaxation/meditation technique held the most promise because it did not require expensive machinery or sophisticated technology: Previous investigators reached similar conclusions and have suggested that the production of a relaxed state alone is a 
useful technique for treating pain and other medical problems (Alexander, 1972; Beary and Benson, 1974).

A recent study by Corbett (1981) compared the effect of EMG biofeedback and progressive relaxation in the treatment of chronic back pain. The present study replicates Corbett's research with some structural variations. The important differences are as follows: Corbett used a design which utilized three groups. Group 1 received EMG and relaxation training; Group 2 received relaxation training only; and Group 3 was a no treatment control group. The present study uses two groups. Group 1 (BF/RT) received EMG biofeedback and relaxation training; Group 2 (BF) received EMG biofeedback training alone. This is a major difference from Corbett's design in that the effects of biofeedback are studied alone in one group, without relaxation training. A third group for control was not included due to a limited number of subjects available to the experimenter. Corbett's study measured the degree of muscle relaxation and the degree of decrease in chronic pain. Corbett also investigated several personality characteristics, taking pre and posttest measures on anxiety, self-regard and self-acceptance, and locus of control. The results of Corbett's study showed that EMG biofeedback training combined with progressive relaxation did produce lower EMG activity than did progressive relaxation alone, or no treatment. Corbett also found a decrease in perceived pain in both experimental groups. However, no significant difference was seen in decreased pain perception between the two groups. 
In addition, both of Corbett's treatment groups showed decreased levels of anxiety, improved scores on self-acceptance and self-regard, as well as a shift from outer to inner-directedness.

The present study is designed to answer the following question: Does EMG biofeedback combined with progressive relaxation have a significantly greater effect on decreased muscle tension and pain perception than EMG biofeedback alone? To this date, no published studies have compared these 2 specific treatment conditions. This study compares the effects of EMG biofeedback combined with progressive relaxation training and biofeedback training alone on individuals suffering from chronic back pain. The scope of the study is limited to investigating EMG levels, subjective measures of pain and relaxation, manifest anxiety, and locus of control. It is assumed by this experimenter that the psychological aspect of pain is at least partly manifested in anxiety and locus of control, as the following reviews indicate.

\section{A Review of The Literature Concerning} Anxiety, Muscle Tension and Pain

Several investigators have examined the difference in personality test scores between chronic pain patients and other groups of patients and normals. For example, Woodforde and Merskey (1972) found no significant difference between pain patients and patients diagnosed as neurotic based on scores on the Eysenck Personality Inventory. 
They did find that patients with pain due to organic lesions had higher anxiety and obsessionality scores than psychogenic pain patients.

Several studies have examined the MMPI profiles of chronic pain patients. Sternbach (1974) found that there was no difference between back pain patients with physical evidences of injury and those without. Both groups exhibited significant elevations on scales measuring hypochondriasis, depression, and hysteria (scales 1, 2, and 3, the "neurotic triad").

Another interesting finding was reported by Capka, Griffin, Harris and Pinsky (1979). These researchers compared MMPI results from 120 female and 47 male chronic pain patients before and after treatment at the City of Hope Pain Center. A hypochondriasis, depression, and hysteria pattern emerged for both males and females on the pretreatment MMPI's, the same pattern obtained by sternbach (1974). Post treatment profiles, however, showed a decrease in neurotic symptoms as the neurotic triad decreased to normal limits. The authors stated that the abnormal elevation of 1,2 , and 3 in the absence of measurable anxiety (normal score on scale 7, MMPI) indicates the presence of "bound" anxiety in chronic pain patients. In other words, these patients are unable to express their anxiety overtly and instead utilize somatization as a means of discharging their inner tension.

Some authors have described what they believe to be 
a characteristic set of personality traits, sometimes known as the "pain personality" (Crue, 1976). These personality factors include depression, preoccupation with somatic symptoms, hostility, and frustraion. Wolfe (1980) disagrees with this position and has stated that there is no such thing as a pain personality. He believes that the personality traits seen so often in chronic pain patients are due to the effects of persistent pain.

For a number of years the relationship between various personality factors and the specific symptom of low back pain has been noted in the psychological and medical literature. Several studies have used the MMPI as a means of identifying personality correlates of the back pain syndrome. According to Gottlieb, Alperson, Koller, and Hockersmith (1979), individuals with back pain and elevated scores on the MMPI scales measuring hysteria, depression, and hypochondriasis have a higher risk of needing multiple operations, remaining in the hospital longer, and reporting poorer subjective and objective results than other individuals with back pain without such MMPI elevations.

Other researchers have found similar results. A recent study by McCreary, Turner, and Dawson (1980) indi-. cated that back pain patients with low scores on distrust, alienation, and somatic concern tended to show good outcome for managing their back pain.

The present study utilized the Taylor Manifest Anxiety Scale (Graham, 1980), a simple questionnaire designed to 
measure anxiety and somatic concern. It is based on items taken from the MMPI and has been used extensively in clinical research. Hentschel (1977) employed the Manifest Anxiety Scale in a study of pain tolerance predictability. Flannery and Marlowe (1981) used it to screen out highly anxious patients in their study of ethnic differences in pain expression. Considering its proven value as a clinical measure of anxiety, the Manifest Anxiety Scale would appear to be a valuable instrument in assessing the presence or absence of high anxiety levels and the relation between anxiety level and pain complaint (Nigl, 1984). Katz, Keilerman and Siegel (1980) have indicated that it may not be clinically feasible to separate anxiety from pain, because many researchers have found that anxiety is a basic affective component underlying pain behavior. Nigl (1984) stresses the importance of integrating anxiety assessing instruments in the clinical assessment of chronic pain. He says, however, that at this time it is impossible to judge which of the anxiety measures that have been used in pain assessment is the most valid or clinically useful.

As Sternbach (1968) has said, it is difficult to know whether anxiety causes pain or pain causes anxiety. What is apparent is that they interrelate with each other, and one symptom is seldom present without the other. An important consideration for the present study is that anxiety tends to cause muscles to tense and increases the sensation of pain.(Selye, 1974). Of particular interest to this in- 
vestigator is whether or not anxious somatic concerns of those with chronic back pain decrease after biofeedback and relaxation training.

A Review of The Literature Concerning Locus of Control In Relation To Biofeedback And Pain

The concept of locus of control was developed by Rotter (1966) based upon his theoretical work in the area of social learning theory. Research by Rotter (1966) has shown that perception of control is a predictor of the manner in which people respond to their outcomes. The concept of locus of control refers to the extent that individuals attribute the reinforcement or punishment they receive as being the result of their own behavior. Internalized persons view themselves as being in control of reinforcement and life events while externalized persons view control of reinforcement and life events as being external to themselves. The Locus of Control Scale used in the present study was developed by psychologists Nowicki and Strickland (1973), and measures how individuals perceive the relationship between their own actions and the consequences of those actions. It was chosen because the form is easy to understand, and takes an average of only 10 to 15 minutes to complete (see Appendix D).

A number of researchers have studied locus of control in relation to the perception of pain. Craig and Best (1977) found that internalizers had significantly higher 
pain tolerance than individuals identified as having an external locus of control. In a study with post-surgical patients, Johnson (1971) found that internalizers demonstrated greater ability to influence their care in the hospital. In other words, they were more assertive than externalizers in discussing treatments with their doctors and making their desires known.

Hall (1979) researched EMG biofeedback in relation to locus of control and found that internalizers were able to gain better mastery in biofeedback techniques than were externalizers. He also found that externalizers improved their performance most when given specific relaxation instructions by a therapist, rather than when they performed relaxation techniques they knew on their own.

Corbett's (1981) research showed that locus of control significantly changed towards internality after biofeedback and relaxation training. Bresler's (1979) studies also seem to indicate a positive relation between internal locus of control and the management of pain. He states that a change from outer-directedness toward inner-directedness tends to motivate the chronic pain patient to accept a personal role in his own treatment process. This in turn motivates the chronic pain patient to leave the sick, helpless role and enter a healthy role where he attempts management of his own pain.

Negative findings, however, have been reported by Clum, Scott, and Burnside (1979). Their correlations be- 
tween pain measures and internal and external locus of control were not significantly different, .38 for internalizers and .39 for externalizers.

Since there appears to be different results found among studies concerned with locus of control, the present study was designed to examine the relationship between biofeedback training and changes in locus of control. It is predicted that after EMG Biofeedback, with or without relaxation training, that locus of control will change towards internality.

Statement of The Problem

Selye (1974) indicates that pain of ten causes muscles to tense and, in turn, the tense muscles cause more pain. On the basis of this information it seems evident that one important aspect in pain management therapy should include muscle relaxation training. The research suggests that EMG biofeedback and progressive relaxation training may be assets in teaching patients how to relax tense muscles. In the process of learning to control muscle tension, patients may then decrease their pain and increase their sense of control in life.

Research has shown that EMG biofeedback can provide the accurate, continuous indicators needed in order for patients to know when and to what degree muscle tension develops in relation to their chronic pain and when and to what degree it diminishes. It can reveal minute differ- 
ences never before known within the realm of human perception. Brown (1974) stated that with the use of EMG biofeedback "you can get inside of the muscle, learn to perceive it directly, and learn to experience its activity. It is a new world of experiences and insights" (Brown, $1974, \mathrm{pg} \cdot 81$.

Progressive Relaxation is another therapeutic technique used for the control of muscle tensions. Jacobson (1938) developed this technique and believed that skeletal muscle tension exacerbated stress-related disorders while muscular relaxation helped to produce opposite effects (Jacobson, 1970). Progressive Relaxation is an exercise in which a group of muscles are contracted and then relaxed, in order to teach the person how to recognize the difference between a tense and relaxed muscle (Jacobson, $1938)$

David Bresler (1979) thinks that relaxation training is an important part of chronic pain control. He stated that:

Many patients with musculoskeletal pain soon find themselves trapped in a vicious cycle. Their discomfort causes them to become anxious and tense, and this tension causes their muscles to tighten. This, in turn, produces more pain, which causes more tension, and so on. It's a devastating cycle from which some people never escape (Bresler, 1979, pg. 196).

\section{Purpose of The Study}

This study has been designed to compare and evaluate treatments involving both EMG biofeedback and progressive 
relaxation training with EMG biofeedback training alone in patients with chronic back pain.

The study includes research on the levels of manifest anxiety, perceived relaxation, perceived pain, EMG activity, and locus of control. As stated earlier, it is assumed that the perception of pain is influenced by psychological variables such as manifest anxiety and inner or outer-directedness.

\section{Research Hypotheses}

The main purpose of this study is to determine the effects of two types of treatment modalities for chronic back pain sufferers. A comparison is made between the effects of EMG biofeedback with progressive relaxation training and EMG biofeedback training alone.

The degree of EMG muscle activity is compared between the two groups. The following hypotheses are posed:

1. EMG biofeedback training combined with progressive relaxation training will produce lower muscle activity than baseline.

2. EMG biofeedback training alone will produce lower muscle activity than baseline.

3. EMG biofeedback training plus progressive relaxation training will produce lower muscle activity than EMG biofeedback alone.

Subjective levels of pain perception and relaxation are compared between the two groups. The following pre- 
dictions are made:

4. Subjective levels of pain will decrease in both groups from baseline.

5. Subjective levels of relaxation will increase in both groups over baseline.

6. The biofeedback and relaxation training group will show a greater improvement in pain decrease and relaxation increase over the group receiving only biofeedback training.

Locus of control scores are compared between the two groups. It is predicted that:

7. Locus of control will change from baseline measures towards internality after treatment in both groups.

8. A greater shift towards internality will be seen in the biofeedback with relaxation training group than in the group receiving biofeedback alone.

Manifest anxiety scores are also compared between the two groups. The following hypotheses are made:

9. Manifest anxiety scores will decrease from baseline in both groups after treatment.

10. A greater decrease in manifest anxiety scores will be seen in the biofeedback with relaxation training groups than. in the group receiving biofeedback alone.

From hypotheses $3,6,8$, and 10 , one can see that the experimenter expects subjects in the biofeedback and relaxation training group to show greater overall improvement on all measures, than subjects receiving biofeedback alone. 
It is assumed by the investigator that the more tools a subject has for managing pain, the more likely he is to play an active part in the recovery process, and to see improvement. 


\section{CHAPTER II}

METHODS

\section{Subjects}

Subjects were 5 male and 11 female patients, ages 21 to 42 , currently involved in therapy at Cascade Chiropractic Clinic in Portland, Oregon. All participants were referred for training by their private doctor. Doctors in the clinic screened patients before admittance into the program. Only those with back pain were included in the study. Subjects were randomly assigned to two treatment groups so that each group contained eight subjects.

Each subject was given an Informed Consent Form explaining the study and procedures of the experiment (see Appendix A). The confidentiality of the data and information was assured for all subjects. Subjects were given the freedom to withdraw from the study at any time. Two subjects did withdraw from the sample, one from each group. One left after 3 sessions and another left after 4 sessions. Their reasons included a geographical move and a job change which inhibited participation. in the study. The final sample size for each group was 7 subjects. 
Apparatus and Materials

An Electromyograph (EMG), Model M-57, produced by $J$ \& J Enterprises, Poulsbo, Washington was used to train subjects to relax their muscles. This unit provided feedback by a Light Emitting Diode (LED) digital display. The LEDs instantly displayed the numeric value of the average amplitude of the EMG for the patient. It presented a discrete number between one and 99 microvolts. As the EMG amplitude decreased or increased according to muscle tension during the biofeedback session, the numeric value displayed also decreased or increased. Continuous visual feedback, of the EMG microvolt readings, was given throughout the entire session. Therefore, these numbers on the visual display served both as feedback and as the response measure indicating degree of muscle tension. The lower the number, the lower the muscle tension. The ideal goal was to reach an EMG level between one and three.

An audio cassette recording of a progressive relaxation exercise was made during the initial session for each subject in the group receiving relaxation training with biofeedback. Jacobson's (1938) procedure for progressive relaxation was used (see Appendix B).

Each subject was asked to complete a battery of pretests and post-tests including: an EMG baseline, a Manifest Anxiety Scale (MAS), a Perceived Pain (PP) Scale, a Perceived Relaxation (PR) Scale, and an Internal Locus of Control (ILC) Scale. 
The Manifest Anxiety Scale. The Manifest Anxiety Scale (MAS) was originally developed by Taylor (1951) to select experimental subjects with high and low anxiety (see Appendix $C)$. The 50 items in the MAS cover a rather wide variety of behaviors. Whereas many of the items clearly deal with overt signs of anxiety (e.g., sweating, blushing, shakiness), other items contain subjective reports of feeling nervous, tense, anxious, upset, etc. There also are many items that involve somatic complaints le.g., nausea, headaches, diarrhea, stomach troubles). Difficulties in concentration and feelings of excitement and/or restlessness also are suggested by some of the items. Some items suggest lack of self-confidence, extreme sensitivity to the reactions of other people, and feelings of unhappiness and uselessness. The items are keyed'in such a way that higher scores are indicative of greater anxiety (Graham, 1980). Research has documented the reliability and validity of the Manifest Anxiety Scale. Hilgard, Jones, and Kaplan (1951) reported a split-half reliability coefficient of .92 for the MAS, and Gocka (1965) obtained a Kuder-Richardson 21 (internal consistency) value of .92 for 220 male Veterans Administration psychiatric patients. Tayior (1953), using a sample of college students, obtained testretest reliability coefficients of $.89, .82$, and .81 over periods of 3 weeks, 5 months, and 17-19 months, respective$1 \mathrm{y}$

The MAS showed moderately high correlations with the 
State-Trait Anxiety Inventory, and Spielberger, Gorsuch, and Lushene (1970) felt that the two scales could be used alternately. Taylor's MAS inventory was chosen for the present study due to its practical utility and brevity. It was also chosen because of its focus on somatic concerns which may help to indicate the presence of "bound" anxiety as discussed earlier by Capka et al. (1979).

Perceived Pain/Relaxation Scales. The Perceived

Pain and Relaxation Scales were developed by Corbett (1981) for studying the effectiveness of biofeedback on chronic back pain (see Appendix D). The measurement is based upon the patient's subjective rating on a scale of 1 to 5 of his or her perceived pain and perceived relaxation. The number 1 represented total freedom from pain and very relaxed, whereas the number 5 represented extreme pain and very tense.

Locus of Control Scale. The Locus of Control scale used in this study was developed by psychologists Nowicki and Strickland (1974) (see Appendix E). The concept "locus of control" is concerned with whether an individual believes in an internal or external control of his life. People who believe that luck, chance, or the actions of others determines what happens to them are said to view their lives as being generally externally controlled. Those who believe the direction of their life is determined by their own actions generally score high on levels of internal control. The Locus of control scale measures how 
individuals perceive the relationship between their own actions and the consequences of those actions. This test was used due to its brevity and simplicity.

\section{Procedure}

Sixteen subjects from Cascade Chiropractic Clinic were randomly assigned to two treatment groups. The first group was given EMG biofeedback and relaxation training. The second group was given EMG biofeedback training alone.

All 16 subjects were given a pre-test battery consisting of (1) EMG biofeedback baseline reading, (2) Taylor's Manifest Anxiety Scale, (3) Corbett's Perceived Pain and Perceived Relaxation Scale, and (4) Nowicki and Strickland's Locus of Control scale. At the end of the treatment period, the 14 remaining subjects were given the same four tests for the post-test battery.

During the first session subjects met with the investigator for one hour. Directions and explanations were given concerning the purpose of the study and the content of the tests to be completed. Upon the completion of the pre-test battery, an EMG biofeedback baseline reading was taken on each subject. Electrodes were placed on the specific set of muscles involved in the subject's pain. The electrodes were placed at one-inch intervals with the ground electrode placed in the middle position. The electrode sites were marked with indelible ink for greater consistency across sessions. 
All subjects were instructed to relax to the best of their ability while seated in a recliner chair that was set in a reclining position. Subjects were not given any visual feedback. The baseline reading was taken for 15 minutes towards the end of the initial session. This same procedure was followed in the final session for post-testing.

Each subject in Group 1 (BF/RT), those being treated with both EMG biofeedback and relaxation training, was trained with the EMG biofeedback. machine two days a week for three weeks. Each training session lasted 30 minutes. The electrodes were placed at the initial baseline site. Ninety microvolt entries were recorded for each subject during a thirty minute session. Scores were collapsed, and three averaged readings were recorded for each subject per session. With the subject reclining in the chair, the EMG machine was placed at eye level so that the visual feedback was easy to read without strain. Subjects were instructed to lower the number on the digital display by relaxing.

In addition to the feedback of the EMG machine, the subjects in these groups were given positive reinforcement by the experimenter every time they lowered their EMG activity more than one microvolt. Subjects in this group were instructed to use the audio cassette relaxation tape (recorded during the initial session) once a day for the entire three weeks of training. 
Subjects in Group 2 (BF) received the same biofeedback training as Group 1. However, subjects received no progressive relaxation training, and were not read a relaxation exercise by the experimenter during the biofeedback sessions. 


\section{CHAPTER III}

\section{RESULTS}

The data collected from the pretraining and posttraining of the two treatment groups are presented in this chapter. Five different dependent variables were recorded: (1) EMG activity, (2) Perceived Pain, (3) Perceived Relaxation, (4) Locus of Control, and (5) Manifest Anxiety. The independent variables included EMG biofeedback combined with Progressive Relaxation (BF/RT) training and EMG biofeedback training alone (BF). Results from the dependent measures will be presented in the following paragraphs.

\section{EMG Activity}

An Electromyograph (EMG) was used to train subjects to relax their muscles. A mean score was calculated for each subject for the pretest day and also for the posttest day. Each subject's mean represents the average of all microvolt readings recorded that day. Mean and standard deviations were then calculated for the pretraining and posttraining scores of both groups. The results showed that the mean EMG levels for the BF/RT group were 7.88 (Standard deviation $(S D=2.29)$ microvolts in the pretraining measure and $3.27(S D=1.25)$ in the posttraining meas- 
ure. The BF group means showed $9.98(S D=7.30)$ microvolts in the pretest and $3.27(S D=1.35)$ microvolts in the posttest.

These results indicate a decrease in muscle tension for both groups following training. A two factor analysis of variance with repeated measures on one factor was calculated to obtain the outcome of the overall treatment effect. A significant difference in EMG activity between pre and posttraining measures for both groups was found where $E(1,12)=18.41, \underline{p}<.05$. No significant difference was found in EMG levels between the two groups (see Appendix for the raw data plus more detailed results of the ANOVA).

\section{Perceived Pain/Perceived Relaxation}

The perceived pain and perceived relaxation measurements were based upon 2 separate subjective ratings by the patient of his pain and relaxation levels. Both scales included a rating spread from 1 to 5 where the number 1 represented total freedom from pain and a very relaxed state and the number 5 represented extreme pain and a very tense state of being. The subjects in each group were asked to indicate the general pattern of their perceived pain and their perceived relaxation at 9:00 A.M., 1:00 P.M., and 8:00 P.M. during the past few days. The scores were then averaged for the day. Since the analyses indicated no significant differences between the A.M., Noon, and P.M. responses, the scores reported here represent an average a- 
cross these three reports. (Note, however, that time of day was one of the factors analyzed in these ANOVAS).

Mean scores and standard deviations for perceived pain and relaxation of the two groups before and after treatment were calculated. The means were obtained by averaging the collapsed (A.M., Noon, and P.M.) perception scores obtained for each subject during pre and posttraining sessions. The results showed that mean scores on pain perception for the BF/RT group were 3.24 (SD $=.87$ ) in the pretest and $2.24(S D=1.09)$ in the posttest. The $B F$ group averages on pain perception revealed the mean scores of $3.25(S D=.97)$ in the pretest and $2.47(S D=.96)$ in the posttest.

The perceived relaxation measures resulted in mean scores of $3.73(S D=.67)$ in the pretest and $2.78(S D=$ 1.10) in the posttest for the BF/RT group. The BF group means were $3.17(S D=.51)$ in the pretest measure and 2.77 $(S D=.67)$ in the posttest.

The results seem to suggest that an overall decrease in pain and improvement in relaxation occurred after training. Two separate three-factor analyses of variance with repeated measures on two factors were used to analyze the perceived pain and relaxation measures. A significant decrease in pain was found in both groups after treatment where $\underline{F}(1,12)=15.15, \underline{p}<.05$. Perceived relaxation also significantly increased in both groups after training where $\underline{E}(1,12)=14.70, \underline{p}<.05$. No difference was found between 
the two groups on either of these measures (see Appendix F for the raw data plus more detailed results of the ANOVA).

\section{Locus of Control}

The Nowicki-Strickland Locus of Control Scale was used to measure how patients perceived the relationship between their own actions and the consequences of those actions. A series of 40 questions were answered by all 14 subjects. Scores from 0-8 represent the range for low scorers. Average scores usually range between 9 and 16 on the test, and high scores fall in the range of 17-40. High scores represent the external control end of the scale whereas low scores represent the internal control end of the scale. Those who score in the average range often combine internal and external control beliefs depen-1 ding on the specific situations they encounter.

Mean and standard deviations for the 7 subjects in each of the 2 groups before and after treatment were calculated. Results showed that means for Group 1 were 11.71 $(S D=3.9)$ in the pretest and $11.8(S D=4.53)$ in the posttest. Group 2 scores were $8.5(S D=4.19)$ in the pretest and $6.57(S D=2.76)$ in the posttest.

It appears that a slight change towards internality occurred only in the BF group. In order to analyze the treatment effects, a two factor analysis of variance with repeated measures on one factor was calculated. The difference between the two groups approached significance $\underline{F}(1,12)=4.49, \underline{p}<.10$ (see Appendix $F$ for raw data plus 
more detailed results of the ANOVA).

Manifest Anxiety

The Taylor Manifest Anxiety Scale was used to detect somatic concern and anxiety levels in the 14 subjects studied. Each subject completed the questions on the MAS before and after treatment. The items are keyed in such a way that higher scores are indicative of greater anxiety.

Mean and standard deviation scores for the two groups before and after training were calculated. Results showed that the means for the $B F / R T$ group were 23.42 (SD $=9.23$ ) in the pretest and $22.43(S D=11.70)$ in the posttest. The BF group scores reflected averages of 19.43 (SD $=$ $11.44)$ in the pretest and $18.0(S D=8.44)$ in the postest. These calculations suggest that patient anxiety levels did not change as a result of either treatment condition. In order to analyze the overall effect of treatment, a twofactor analysis of variance with repeated measures on one factor was calculated. No significant differences were detected (see Appendix $F$ for raw data plus more detailed results of the ANOVA). 
CHAPTER IV

\section{DISCUSSION}

The experimental design utilized in the present study permitted a comparison of the effect of EMG biofeedback combined with relaxation training and EMG biofeedback alone on chronic back pain patients. It was predicted that EMG biofeedback training combined with progressive relaxation training would produce lower muscle activity than baseline.

Biofeedback training combined with relaxation training did produce lower EMG activity than baseline. These results stand in agreement with the results of research previously mentioned (Kravitz et al., 1978; Fisher-Williams et al., 19811 .

The second hypothesis stated was that EMG biofeedback training alone would produce lower muscle activity than baseline. Data results showed that this treatment condition did produce lower EMG muscle activity than baseline. These findings differ somewhat from results found by Freeman et al., (1976); the group receiving biofeedback training in his study did not show a significant decrease in muscle activity over baseline after treatment. Freeman et al.,(1976) detected mixed results in his research. Results from his study showed that four of the eight subjects trained with 
biofeedback had muscle activity levels lower than baseline after treatment. The other four did not. Findings from the present study differ from these researchers, in that all 7 subjects achieved lower levels of muscle tension after treatment.

The third prediction was that EMG biofeedback combined with progressive relaxation training would produce lower muscle activity than EMG biofeedback alone. No significant effects were found between the two groups. These findings seem to suggest that EMG biofeedback training, in and of itself, is a very powerful tool for reducing muscle tension. It appears that the exercises in progressive relaxation did not facilitate further improvement in lowering muscle activity.

The fourth prediction stated was that subjective levels of pain would decrease in both groups from baseline. Results indicated that an overall decrease of pain perception did occur after training in both groups. These findings seem to suggest that learning to relax tense muscles, whether through EMG training alone, or EMG combined with progressive relaxation exercises, tends to decrease the perception of pain. These findings stand in agreement with the results that Freeman et al. (1976), Nouwen et al. (1976) and Corbett (1981) obtained in their studies.

The fifth hypothesis was that subjective levels of relaxation would increase in both groups over baseline. The results indicated an overall improvement in relaxation 
after treatment in both groups. These results also parallel the findings obtained in Corbett's (1981) study.

The sixth prediction stated was that the biofeedback and relaxation training group would show a greater improvement in pain decrease and relaxation increase over the group receiving biofeedback training alone. No significant differences between the groups were found on either scale. It appears that progressive relaxation training does not add any further improvement to treatment in effecting a decrease in the perception of pain or an increase in relaxation.

It is interesting to compare these results with those found by corbett $(1981)$. In her study, which compared EMG biofeedback combined with progressive relaxation training to progressive relaxation alone, she found that both groups significantly decreased their pain perception, and increased their perceived relaxation. No significant differences in improvement were found between her groups. Corbett's (1981) data seems to suggest that progressive relaxation training alone and biofeedback with relaxation training are equally effective in decreasing pain and increasing relaxation. It is possible that while both techniques are effective, a patient's perception can only improve to a certain degree regardless of the number of techniques added to treatment.

In the present study it was also predicted that locus of control would change from baseline towards internality after treatment in both groups. Based on the statistical analysis, no significant overall differences in pretest/ posttest measures were detected. In addition, no signifi- 
cant difference in the treatment by pretest/posttest interaction was found. These findings do not fall in the same direction as those reported by Corbett (1981) and Bresler (1979) in which a change from outer to inner-directedness was found after treatment.

The eighth prediction made in this study was that a greater shift towards internality would be seen in the biofeedback with relaxation training group than in the group receiving biofeedback alone. Results showed no significant treatment by pretest/posttest interaction. However, the non-significant differences obtained actually fell in the opposite direction from that predicted. Such findings tend to indicate that relaxation training did nothing to enhance biofeedback training in effecting a change towards internal locus of control.

The present study predicted that manifest anxiety scores would decrease from baseline in both groups after treatment, and that a greater decrease in anxiety scores would be seen in the BF/RT group than in the BF only group. These predictions did not prove to be significant. No decrease in anxiety levels were detected after treatment. The findings seem to indicate that anxiety levels were not affected by either treatment condition.

There is a possible explanation for obtaining these non-significant results. First, it was observed by the experimenter that during the three weeks of training, several subjects encountered major circumstantial stressors or hardships. One subject's husband threatened to leave her, an- 
other was served a summons regarding a law suit, and two others lost their jobs. It is safe to assume that these events would facilitate an increase in anxiety, which may have confounded the effects of $B F$ and $B F / R T$ training on anxiety levels. When the anxiety scores of these four individuals were dropped from the data, much broader differences were detected between the mean scores for both groups in the pretest and posttest. The BF/RT group mean scores were 24.0 in the pretest and 19.4 in the posttest, whereas the BF group means were 22.6 in the pretest and 18.6 in the posttest.

In conclusion, it appears that both biofeedback combined with progressive relaxation and biofeedback training alone are effective in lowering muscle activity and perceived pain, and in increasing perceived relaxation. However, from the results of this study, it is impossible to conclude thát one treatment method is more effective than the other.

\section{Implications of The Study}

As this study indicates, biofeedback and relaxation training are useful methods to incorporate when treating those with chronic back pain. It is obviously important that a patient learn how to take an active part in his own pain management. Through EMG biofeedback training a patient can learn to control and lower his muscle tension, and can reduce his pain and increase his ability to relax.

As a: patient learns these techniques he is able to 
break the vicious cycle of tension--pain--tension--pain. Not only can he learn to circumvent tension so that pain is reduced, but he can also train his body to experience the opposite of tension, relaxation. The positive by-products of this are obvious. The patient can begin to step out of a sick, helpless role, into a role of managing his pain.

\section{Limitations of The Study}

There are a couple of limitations associated with this study which may limit any interpretation of the results and generalizability to other chronic pain patients. First, within the time constraints of the study, only a small number of subjects were available to the experimenter. Second, no control group was used as a point of comparison to the other two groups. And third, the placebo response may have also played a part in the data obtained. The one-to-one relationship of the therapist-patient in the biofeedback training could have produced a placebo effect due to the verbal and non-verbal reinforcement given by the therapist. A placebo control group would be necessary to determine the extent of this influence.

\section{Suggestions For Future study}

In general, the use of EMG biofeedback and relaxation training in the treatment of chronic pain appears to be very promising. However, further research is needed in the future to determine the efficacy of various approaches and treatment combinations. Hopefully, sufficient research 
will be conducted in the near future to determine conclusively whether EMG biofeedback is more effective than relaxation training or whether biofeedback may provide more effective results than can be obtained with relaxation or other behavioral methods used alone or in various combinations.

Since back pain patients are a heterogeneous group, it may prove helpful for future research to identify which patients would respond best to biofeedback. This could be done by matching subjects as to age, sex, etiology of pain, etc. In addition, follow-up studies would be beneficial in order to estimate the longevity of treatment effects. For example, it may be that while there is no difference found immediately in posttraining between subjects given biofeedback alone as compared with subjects given biofeedback plus progressive relaxation, a follow-up test might indicate a difference. It is not uncommon in clinical studies to find significant differences at a follow-up test where no differences were found at a posttest (Frank, $1978)$ 


\section{REFERENCES}

Alexander, A. B. 1972. "Systematic relaxation and flow rates in asthmatic children: Relationship to emotional precipitants and anxiety," Journal of Psychosomatic Research, $16: 405-409$

Avant, L. and Helsen, H. 1973. "Theories of perception," in B. Wolman (ed.), Handbook of General Psychology, Englewood Cliffs, New Jersey: Prentice-Hall.

Beary, J.F. and Benson, H. 1974. "A simple physiologic technique which elicits the hypometabolic changes of the relaxation response," Psychosomatic Medicine, 36 : $115-119$.

Bonica, J. 1980. Pain. New York: Raven Press.

Bresler, D. E. 1979. Free Yourself From Pain. New York: Simon and Schuster.

Brown, B. B. 1974. New Mind, New Body. New York: Harper and Row.

Capka, D., Griffin, S., Harris, G., and Pinsky, J. 1979 . "Selected psychometric evaluations before and after treatment on a pain unit," in B. Crue (ed.), Chronic Pain, New York: Spectrum Publications.

Chapman, J. 1980. "Pain and perception: Comparison of sensory decision theory and evoked potential methods," in J. Bonica (ed.), Pain. New York: Raven Press.

Clum, G., Scott, L., and Burnside, J. 1979. "Information and locus of control as factors in the outcome of surgery," Psychological Reports, 45: 867-873.

Corbett, K. W. 1981. "A comparison of EMG biofeedback and progressive relaxation used in the treatment of chronic pain," Dissertation Abstracts International, 31 : $(9-A), \quad 4886$.

Craig, K. and Best, A. 1977. "Perceived control over pain: Individual differences and situational determinants," Pain, $3: 127-135$. 
Crue, B. L., and Carregal, E. J. 1975. "A pain begins in the dorsal horn with a proposed classification of the primary senses," Pain: Research and Treatment, New York: Academic Press.

Crue, B. 1976. Neurophysiology of Pain: Advances in Stimulation and Surgical Treatment. New York: Biomonitoring Applications.

Fisher-Williams, M., Nigl, A., and Sovine, D. 1981. A Textbook of Biological Feedback. New York: Humān Sciences Press.

Flannery, R. and Marlow, N. 1981. "Ethnicity as a factor in the expression of pain," Psychosomatic Medicine, 22 : $39-50$.

Frank, J. 1978. "Therapeutic components shared by all psychotherapies," in J. H. Harvey and M. M. Parks (eds.), American Psychological Association Master Lecture Series, 1: 15 .

Freeman, C., Calsyn, D., and Louks, J. 1976. "The use of the Minnesota Multiphasic Personality Inventory with low back pain patients," Journal of Clinical Psychololgy, 32 : $294-298$.

Gocka, E. 1965. American Lake Norms for 200 MMPI Scales. Unpublished material.

Gottlieb, H., Alperson, B., Koller, R., and Hockersmith, V. 1979. "An innovative program for the restoration of patients with chronic pain," Physical Therapy, 59: 996-999.

Graham, J. 1980. The MMPI: A Practical Guide. New York: Oxford University Press.

Hall, W. E. 1979. "Locus of control in electromyograph feedback," American Journal of Clinical Biofeedback, 2 : $\quad 92-93$.

Hentschel, V. 1977. "Pain tolerance and its predictability through ratings and psychological tests," Archives of Psychology, 129: 39-54.

Hilgard, E. R., Jones, L. V., and Kaplan, S. J. 1951. "Conditioned discrimination as related to anxiety," Journal of Experimental Psychology, 42: 94-99.

Jacobson, E. 1938. Progressive Relaxation. Chicago: University of Chicago Press. 
1970. Modern Treatment of Tense Patients.

Springfield, Illinois: Charles C. Thomas.

Johnson,: D. N. 1971. "The dynamics of structured tests," Psychological Review, $78:$ 239-249.

Katz, E., Kellerman, J., and Siegel, S. 1980. "Behavioral distress in children with cancer undergoing medical procedures: Developing considerations," Journal of Consulting Clinical Psychology, $48: 356-\overline{36}$.

Keefe, F. 1982. "Behavioral assessment and treatment of chronic pain: Current status and future directions," Journal of Consulting and Clinical Psychology, 50 : $\overline{8} 96-911$.

Kravitz, E., Moore, M., Glaros, A., and Stauffer, T. 1978 . "EMG feedback and differential relaxation training to promote pain relief in chronic low back pain patients," Biofeedback.Self-Regulation, $3: 217$.

Mackworth, N. 1950. Research on the Measurement of Human Performance. Medical Research Council special Report, No. 268. London: H. M. Stationary office.

McCreary, C., Turner, J., and Dawson,.E. 1980. "Emotional disturbance and chronic low back pain," Journal of Clinical Psychology, 36: 709-715.

Melzack, R. and Wall, P. 1965. "Pain mechanisms: A new theory," Science, 150: 971-979.

Melzack, R. 1973. The Puzzle of Pain. New York: Basic Books.

1980. "Pain mechanisms and stress," Stress, $1: 18-23$.

Nigl, A. 1980. "EMG feedback as an aversive conditioning procedure for treatment of chronic pain," in $\mathrm{N}$.

Ishinaka (ed.), Biofeedback and Medication. Tokyo, Japan: Sushin shobo Publishers.

- 1984. Biofeedback and Behavioral Strategies in Pain Management. New York: Spectrum Publications.

Nouwen, A. and Solinger, J.W. 1976. "The effectiveness of EMG biofeedback training in low back pain," Biofeedback and Self-Regulation.

Nowicki, S., and Strickland, G. 1973. "Locus of Control Scale," in R. Aero and E. Weiner (eds.), The Mind Test. New York: William Morrow and Compañy. 
Rotter, J. 1966. "Generalized expectancies for internal vs. external control of reinforcement," Psychology

Monographs, $80: 1-33$.

Seer, P. 1979. "Psychological control of essential hypertension: Review of the literature and methodological critique," Psychological Bulletin, 86: 1015-1043.

Selye, H. 1974. Stress Without Distress. New York: New American Lib rary.

Spielberger, C., Gorsuch, R. L., and Lushene, R. E. 1970 . State-Trait Anxiety Inventory Manual. Palo Alto, California: Consulting Psychologists Press.

Sternbach, R. A. 1968. Pain: A Psychophysiological Analysis. New York: Academic Press.

- 1974. Pain Patients: Traits and Treatments.

New York: Ac ademic Press.

Taylor, J. A. 1951. "The relationship of anxiety to the conditioned eyelid response," Journal of Experimental Psychology, 41 : $81-92$.

1953. "A personality scale of manifest anxiety," Journal of Abnormal and Social Psychology, 48: $285-$ 290 .

Todd, J. and Belar, C. 1980. "EMG biofeedback and chronic low back pain: Implications of treatment and failure," American Journal of Clinical Biofeedback, 3: $114-117$.

Urban, B. J. 1982. "Therapeutic aspects in chronic pain," Behavior Therapy, $13: 430-437$.

Weisenberg, M. 1977. The Control of Pain. New York: Psychological Dimensions.

Wolfe, B. 1980. "Measurement of human pain," in.J. Bonica (ed.), Pain. New York: Raven Press.

Woodforde, J. and Merskey, H. 1972. "Personality traits of patients with chronic pain," Journal of Psychosomatic Research, 16: $167-172$. 
APPENDIX A

INFORMED CONSENT FORM 
The purpose of this study is to examine the effectiveness of electromyographic (EMG) biofeedback together with progressive relaxation.

Measurements will be made before and after a threeweek training period using EMG biofeedback and progressive relaxation for one group and biofeedback training only for the second group.

Biofeedback training will last three weeks, including nine thirty-minute sessions. Progressive relaxation training will be taught the first day of the training program, and the subject will be asked to use the progressive relaxation tape three times a day for the three-week period.

Questions regarding procedures or other aspects of this study will be answered by the investigator upon request of the subject.

The subject is free to discontinue participation in the experiment at any time without prejudice to the subject. Participation is entirely voluntary and the project may not be of direct benefit to the subject.

All information and data derived from this study will be held in strict confidence and will be used solely for the stated purpose of this investigation.

I have read and understand all of the above information and $I$ agree to participate in the study. 
APPENDIX B

JACOBSON'S PROGRESSIVE RELAXATION TECHNIQUE 
Jacobson's Progressive Muscle Relaxation Instructions

The instructions that follow will teach you how to relax yourself whenever you feel tense. Even though you may not feel anything, I want you to follow the instructions step by step. As you do so you will learn how to relax.

Make yourself comfortable either in a reclining chair or lying down. As you do that I want you to settle back as comfortably as you can, close your eyes, and get yourself relaxed to the best of your ability... As you relax like that, clench your right fist, just clench your fist tighter and tighter, and feel the tension as you do so, now relax... Let the fingers of your right hand become loose and observe the contrast in your feelings...Just let yourself go and try to become more relaxed all over... Once more, clench your right fist rather tight; squeeze it down, hold it and notice the tension; feel the tension in your right fist, your hand, your forearm... All right, now let go. Just relax. Let your fingers straighten out... Notice the difference once more... Now repeat that with your left fist. Clench your left fist while the rest of your body relaxes... Clench the fist tighter and feel the tension... Now relax...Again, enjoy the contrast.... Repeat that once more...Make that left fist tight and tense... Hold it tight... Now do the opposite of tension...Relax... Feel the difference... Just continue relaxing like for a while.... Now clench both fists; clench them tighter, and 
feel the tension in your forearms. Study the sensations;

feel the cramping, the aching... Relax...straighten out your fingers and feel the relaxation...Continue to relax... Just relax your bands and forearms more and more....

Now bend your elbows and tense your biceps... Tense them harder...Study the tension...All right, straighten out your arms; let them relax and feel the difference again...Just let the relaxation develop... Say to yourself, "I feel warm and relaxed, warm and relaxed."... Once more tense your biceps again...Hold the tension; hold it tight, and observe it carefully... Now straighten out your arms; relax...Relax to the best of ability...Just relax your arms back to a comfortable position and let the relaxation proceed to the rest of your body...Y Your arms should feel comfortably heavy if you allow them to relax...Concentrate on the true relaxation of the arms without any tension... Get them comfortable; just let them relax further and further...Even when your arms seem fully relaxed, try to go that extra little bit further...Try to achieve deeper and deeper levels of relaxation...... Concentrate on letting all your muscles go loose and heavy...... Say out loud, "My muscles feel warm, loose and heavy.".."My muscles feel warm, loose, and heavy."...

Wrinkle up your forehead now; wrinkle it tighter, still tighter. Feel the tension in your forehead. Just hold it..... Now stop; stop wrinkling your forehead. Re$1 \mathrm{ax}$ and smooth it out... Let the entire forehead become smooth as the forehead continues to relax...Just let it 
flatten out and relax...Feel the relief of tension as you relax...Relax, relax...

Now close your eyes tight...Pull them tighter and feel the tension...Just feel the tension... Now relax, relax, completely. :Just let completely go... Keep your eyes gently and comfortable closed... Notice the relaxation around your eyes....... Now clench your jaw... Bite your teeth together...Bite hard. Study the tension throughout the jaw...study the tension in your cheek muscles... Now relax your jaw...Appreciate the relaxation...Feel the relaxation all over your face, all over your forehead, your eyes, your jaw, your lips, your tongue... Let the relaxation progress further and further, deeper and deeper... Repeat out loud, "My face feels heavy, warm, and relaxed."... "My face feels heavy, warm, and relaxed."...

Now tense your front neck muscles. Make a "web" neck... Now relax...Relax...Relax...Press your head back as hard as you can and feel the tension in the back of the neck... Now let your head return forward to a comfortable position...study the relaxation...Just let the relaxation develop.......Feel that nice, warm, heavy feeling...shrug your shoulders up now. Shrug them up hard; just bring them right up and hold the tension...Drop your shoulders now and feel the relaxation, feel the relaxation in your neck, your shoulders...Just let them completely drop down... Shrug your shoulders again; feel the tension in your shoulders and your back...Drop your shoulders once more... Let the relaxation spread deep within your shoulders, right in- 
to your back muscles... Relax your neck, throat, your jaw, and all the other facial muscles as pure relaxation takes over. Just let it go deeper and deeper and deeper...Just relax your entire body to the best of your ability...... Feel the comfortable heaviness that accompanies relaxation... Just breathe easily and freely in and out. Regularly, deeply, slowly, and rhythmically in and out... Notice how the relaxation increases as you exhale... As you breathe out just feel the relaxation....

Now breathe in and fill your lungs again; inhale deeply and hold your breath; study the tension......All right, now exhale; let the walls of your chest go loose and limp, and let it push the air out automatically...... Just continue relaxing and breathing gently and rhythmically. Feel the relaxation and enjoy it...Just feel the relaxation every time you let that air blow out... Every time you let your chest fall down, let it push the air out and feel the relaxation..... Let the rest of your body relax as much as possible, as you breathe slowly and rhythmically.

Now once again, take a slow, deep breath in-and-hold it... okay, let your chest collapse... Breathe out and appreciate the release that comes from letting your chest go and push the air out of your lungs... Just breathe normally now... regularly and rhythmically...

Continue relaxing your chin... Let the relaxation spread to your back and shoulders, to your neck and arms. Just completely let go. Just let yourself go competely 
limp.......Next give attention to your abdominal muscles, your stomach area... Tighten your.stomach mascles. Push out your stomach muscles, make them hard...hard as a board ... Notice the tension in your stomach muscles...Now relax and let the muscles loosen and notice the contrast... Once more press and tighten your stomach muscles hard. That's it, hard. Hold it and study the tension in the muscles... Study the tension in the stomach muscles... And relax..... Notice the general well-being that comes with relaxing your stomach...Feel the tension... And relax again...Continue breathing normally and equally........ Now this time pull your stomach in and hold it in tension...Hold it hard ...Hold and feel the tension...okay, now relax...Just let your stomach muscles relax... Let the sensation dissolve into relaxation... deeper and deeper...Each time you breathe out notice the rhythmic relaxation both in your chest and stomach...Just let go of azl thestersion...Just let yourself go completely limp... And relax...Just feel that sense of well-being...that nonchalant "I don"t care" attitude... Just let completely go... Feel that relaxation go all over your whole body muscles...

Flex your thighs now... Flex them by pressing on your heels as hard as you can... Feel the tension...Feel the tightness in the back of your thighs...Press hard...Relax now and note the difference... Just feel the warmth, the aching sensation in the thighs as you relax completely.... Flex your thigh muscles again, and hold the tension; hold it hard...That's it...That's it, hard... Feel the aching 
in the thigh mascles... Now relax; relax your hips and

thighs...Just allow the relaxation to proceed on its own... Feel the difference... that good warm sensation from relaxation in your thighs...

Now press your feet and toes downward away from your face until the calf muscles become tense and tight...Push hard, that's.it...study that tension now... Relax, relax now... Just feel that warm feeling in the muscles, that tingling sensation... Once again press your feet and toes downward away from your face... Let your calf muscles become tense...hard, cramping..... Now relax, relax your feet and calves... Keep relaxing like that for awhile...Just let yourself relax further and further all over...Relax your feet, ankles, calves, knees, thighs, hips...Feel the difference in your lower body as you relax still further and further...Feel the warmth and heaviness... Let the relaxation spread to your stomach, your waist, your back... Let go more and more...Just let it go that little bit further, completely relax...Just feel that relaxation all over your body... Let proceed to your upper back, chest, shoulders and arms, out to the tips of your fingers... Keep relaxing more and more deeply... Relax your neck, your jaw, and all your facial muscles....Just let them completely relax.... Let yourself relax completely.... Eeep relaxing your whole body like that for awhile...You can become twice as relaxed as you are right now merely by taking a really deep breath...Breathe in deeply. Now hold it... Slowly exhale... Just let your chest walls fall down and push the air out... 
Now breathe in deeply once more. Now exhale; feel yourself becoming heavier and heavier... Feel how heavy and relaxed you have become. Breathe slowly, regularly, and rythmically...Just stay in perfect relaxation. You should not feel any tension from a single muscle in your body. Your whole body becomes progressively heavier and heavier and all your muscles relax... Let go more and more completely... Now give your muscles individual attention... Relax the muscles of your forehead. Just let your entire scalp become smooth... Now relax the muscles in the lower part of your face...Relax the muscles of your jaw, the muscles of your tongue... Give it attention again... Relax the muscles of your forehead, and of the lower part of your face... Relax the muscles of your jaw.. As you do so, your jaw will hang slightly open... Now relax the muscles of your tongue... Relax the muscles of your neck and all of the muscles of your shoulders...Completely relax... Relax the muscles of your trunk and those of your lower limbs...Just let go of any tension you have left; let the relaxation take over completely...Just let yourself relax....

You feel so much at ease now and so very comfortable .... In this state of perfect relaxation you feel completely unwilling to move a single muscle. You feel so lazy, unconcerned, and nonchalant... As you are lying there like that and feel so good, picture the word "eelax" and say the word "relax" quietly and rythmically. Relax...Relax... Feel yourself completely limp...Again, picture the word "relax" and once again say the word "relax"... Now say, "I'm 
calm and relaxed."..."I'm calm and relaxed"..."My body feels warm and heavy."...Do that once more..."I'm calm and relaxed; my body feels warm and heavy. I feel so peaceful and restful. $R-e-l-a-x . " . .$. See the word "relax" and say "relax"; say, "I'm calm and relaxed."..."Relax.". Feel yourself completely tranquil, contented, drowsy and lazy. I feel so good, so warm, and so relaxed......... feel so good, so warm, and so relaxed."...

As you are completely relaxed, totally serene, and tranguil, I will count backwards from four to one. When I get to one you will open your eyes to a very refreshed, wide awake, calm, tranquil, and serene feeling.....Four... Three.... Two..... one.... 
APPENDIX C

TAYLOR'S MANIFEST ANXIETY SCALE 
Taylor Manifest Anxiety Scale

T F 1. My hands and feet are usually warm enough.

I F 2. I work under a great deal of tension.

T F 3. I have diarrhea once a month or so.

I F 4. I am very seldom troubled by constipation.

$T$ T 5. I am troubled by attacks of nausea and vomiting.

$T$ T 6. I have nightmares every few nights.

$T$ T 7. I find it hard to keep my mind on a task or a job.

$T$ F 8. My sleep is fitful and disturbed.

T F 9. I wish I could be as happy as others seem to be.

$T$ F 10. I am certainly lacking in self-confidence.

T F 11. I am happy most of the time.

$T$ F 12. I have a great deal of stomach trouble.

$T$ F 13. I certainly feel useless at times.

T F 14. I cry easily.

T F 15. I do not tire quickly.

T F 16. I frequently notice my hands shake when I try to do something.

T F 17. I have very few headaches.

$T$ F 18. I frequently find myself worrying about something.

$T$ F 19. I hardly ever notice my heart pounding and I am seldom short of breath.

$T F$ 20. I have periods of such great restlessness that I cannot sit long in a chair.

$T$ F 21. I dream frequently about things that are best kept to myself.

T F 22. I believe I am no more nervous than most people.

$t F$ 23. I sweat very easily even on cool days.

$\mathrm{T} F$ 24. I am entirely self-confident.

$T$ F 25. I have very few fears compared to my friends.

$T F$ 26. Life is a strain for me much of the time.

T F 27. I am more sensitive than most people.

T F 28. I am easily embarrassed.

$T$ F 29. I worry over money and business.

$T$ F 30. I cannot keep me mind on one thing.

$T$ F 31. I feel anxiety about something or someone almost all the time.

T F 32. Sometimes I become so excited that I can't get to sleep.

$T$ F 33. I have been afraid of things or people that $I$ knew could not hurt me.

$T$ F 34. I am inclined to take things hard.

T F 35. I love to go to dances.

T F 36. I like parties and socials.

T F 37. I am usually calm and not easily upset.

$T F$ 38. At times I think I am no good at all.

$T F$ 39. I feel hungry most all the time.

T F 40. I worry quite a bit over possible misfortunes.

$T$ F 41. It makes me nervous to have to wait.

$T$ F 42. I have had periods in which I lost sleep over worry.

$T$ F 43. I must admit that I have at times been worried be- 
yond reason over something that really didn't matter.

T F 44. I am a high-strung person.

$T$ F 45. I practically never blush.

$T F$ 46. I blush no more often than others.

$T$ F 47. I am often afraid I'm going to blush.

$T$ F 48. Often, even though everything is going fine for me, I feel that I don't care about anything.

$T$ F 49. I sometimes feel that $I$ am about to go to pieces. 
APPENDIX D

PERCEIVED PAIN AND PERCEIVED RELAXATION SCALE 
CORBETT'S PERCEIVED PAIN AND PERCEIVED RELAXATION SCALE

Name Date

\section{PERCEIVED PAIN}

(Please circle your perceived pain at indicated hours)

$9: 00$ a.m.

$1: 00$ p.m.

8:00 p.m.

Extreme Pain 5

5

5

Moderate Pain

4

4

4

Average Pain

3

3

3

Slight Pain

2

2

2

No Pain

1

1

1

(Please circle your $\frac{\text { PERCEIVED RELAXATION }}{\text { perceived relaxation at indicated hours) }}$

9:00 a.m. 5

Very Tense

Very Relaxed
Tense

Neutral

Relaxed

\section{Very Tense}

5

4

3

2

1

$1: 00$ p.m.

8:00 p.m.

5

4

3

2

1

5

4

3

2 
APPENDIX E

LOCUS OF CONTROL SCALE 
Nowicki-Strickland Locus of Control Scale

1. Do you believe that most problems will solve themselves if you just don't fool with them?

2. Do you believe that you can stop yourself from catching a cold?

3. Are some people just born lucky?

4. Most of the time do you feel that getting good grades meant a great deal to you?

5. Are you often blamed for things that just aren't your fault?

6. Do you believe that if somebody studies hard enough he or she can pass any subject?

7. Do you feel that most of the time it doesn't pay to try hard because things never turn out right anyway?

8. Do you feel that if things start out well in the morning it's going to be a good day no matter what you do?

9. Do you feel that most of the time parents listen to what their children have to say?

10. Do you believe that wishing can make good things happen?

11. When you get punished does it usually seem it's for no good reason at all?

12. Most of the time do you find it hard to change a friend's opinion?

13. Do you think that cheering more than luck helps a team to win?

14. Did you feel that it was nearly impossible to change your parents' minds about anything?

15. Do you believe that parents should allow children to make most of their own decisions?

16. Do you feel that when you do something wrong there's very little you can do to make it right?

17. Do you believe that most people are just born good at sports?

18. Are most of the other people your age stronger than you are?

19. Do you feel that one of the best ways to handle most problems is just not to think about them?

20. Do you feel that you have a lot of choice in deciding who your friends are?

21. If you find a four-leaf clover, do you believe that it might bring you good luck?

22. Did you of ten feel that whether or not you did your homework had much to do with what kind of grades you got?

23. Do you feel that when a person your age is angry at you, there is little you can do to stop him or her?

24. Have you ever had a good-luck charm?

25. Do you believe that whether or not people like you depends on how you act?

26. Did your parents usually help you if you asked them to?

27. Have you felt that when people were angry with you it was usually for no reason at all?

28. Most of the time, do you feel that you can change what 
might happen tomorrow by what you do today?

29. Do you believe that when bad things are going to happen they just are going to happen no matter what you try to do to stop them?

30. Do you think that people can get their own way if they just keep trying?

31. Most of the time do you find it useless to try to get your own way at home?

32. Do you feel that when good things happen they happen because of hard work?

33. Do you feel that when somebody your age wants to be your enemy there's little you can do to change matters?

34. Do you feel that it's easy to get friends to do what you want them to do?

35. Do you usually feel that you have little to say about what you get to eat at home?

36. Do you feel that when someone doesn't like you there's little you can do about it?

37. Did you usually feel that it was almost useless to try in school because most other children were just plain smarter than you were?

38. Are you the kind of person who believes that planning ahead makes things turn out better?

39. Most of the time, do you feel that you have little to say about what your family decides to do?

40. Do you think it's better to be smart than to be lucky? 
Using the scoring Key below, fold this page back on the dotted line and compare your answers on the previous page to the ones on the key. Give yourself one point each time your answer agrees with the keyed answer. Your score is the total number of agreements between your answers and the ones on the key.

\section{Scoring Key}

1. Yes

2. No

3. Yes

4. No

5. Yes

6. No

7. Yes

8. Yes

9. No

10. Yes

11. Yes

12. Yes

13. No

14. Yes

15. No

16. Yes

17. Yes

18. Yes

19. Yes

20. No

21. Yes

22. No

23. Yes

24. Yes

25. No

26. No

27. Yes

28. No

29. Yes

30. No

31. Yes

32. No

33. Yes

34. No

35. Yes

36. Yes

37. Yes

38. No

39. Yes

40. No 
APPENDIX F

RAW DATA AND ANALYSIS OF VARIANCE SUMMARY TABLES 
ANALYSIS OF VARIANCE SUMMARY TABLES

TABLE I

EMG LEVELS PRETRAINING AND POSTTRAINING

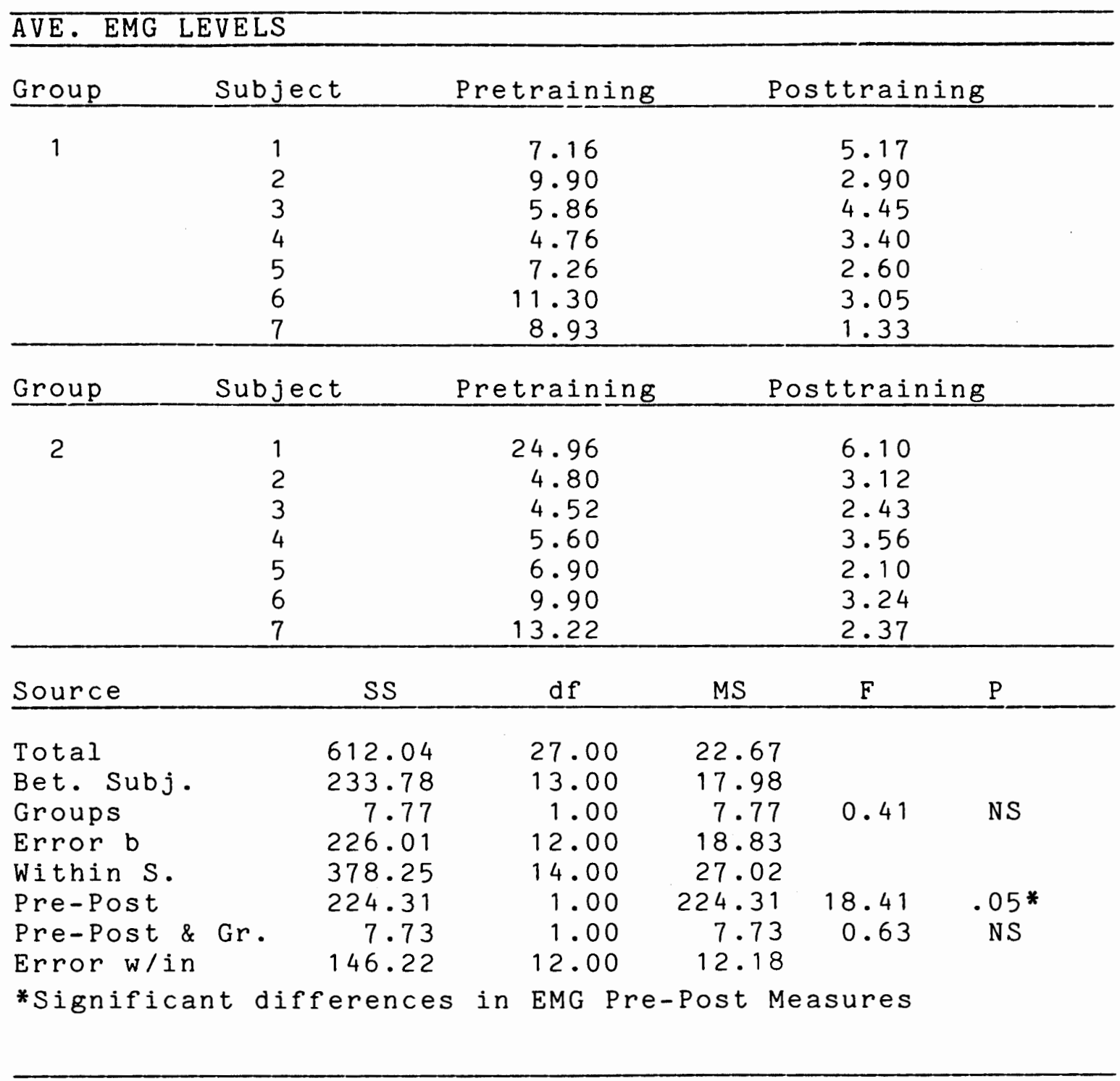


ANALYSIS OF VARIANCE SUMMARY TABLES

TABLE II

PERCEIVED PAIN SCALE SCORES PRETRAINING AND POSTTRAINING

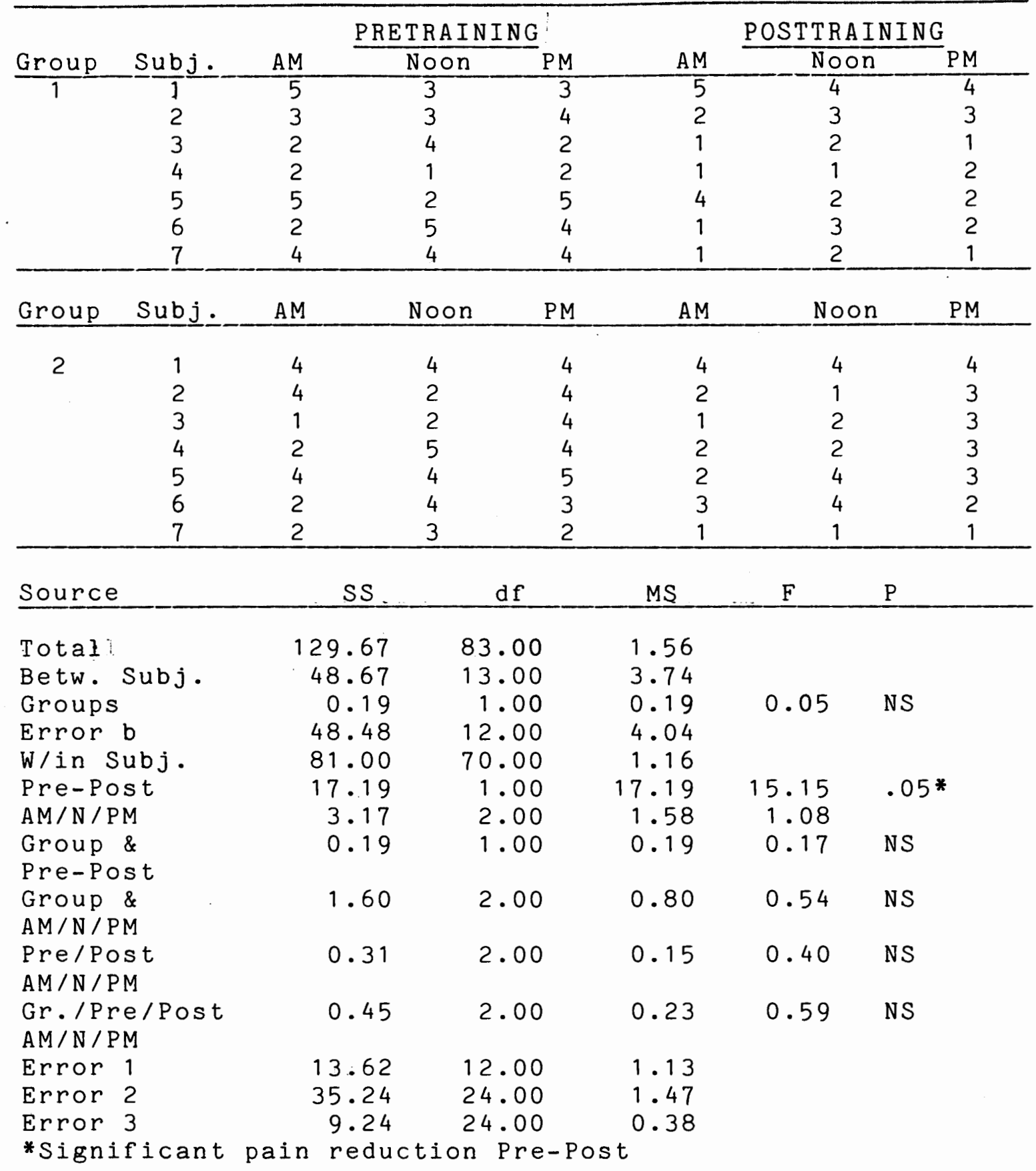


ANALYSIS OF VARIANCE SUMMARY TABLES

TABLE III

PERCEIVED RELAXATION SCALE SCORES PRETEST/POSTTEST

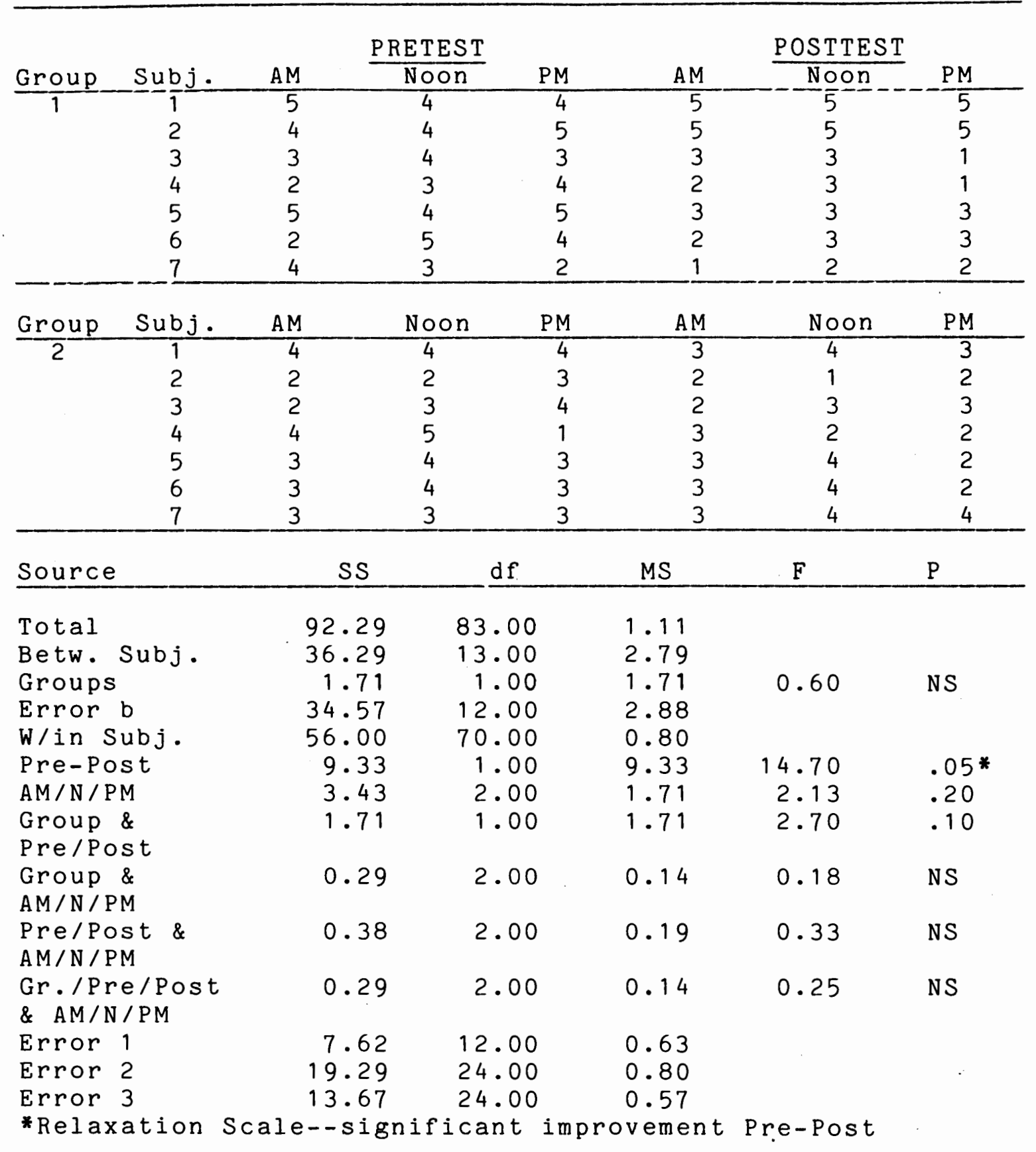


ANALYSIS OF VARIANCE SUMMARY TABLES

TABLE IV

LOCUS OF CONTROL SCORES PRETRAINING AND POSTTRAINING

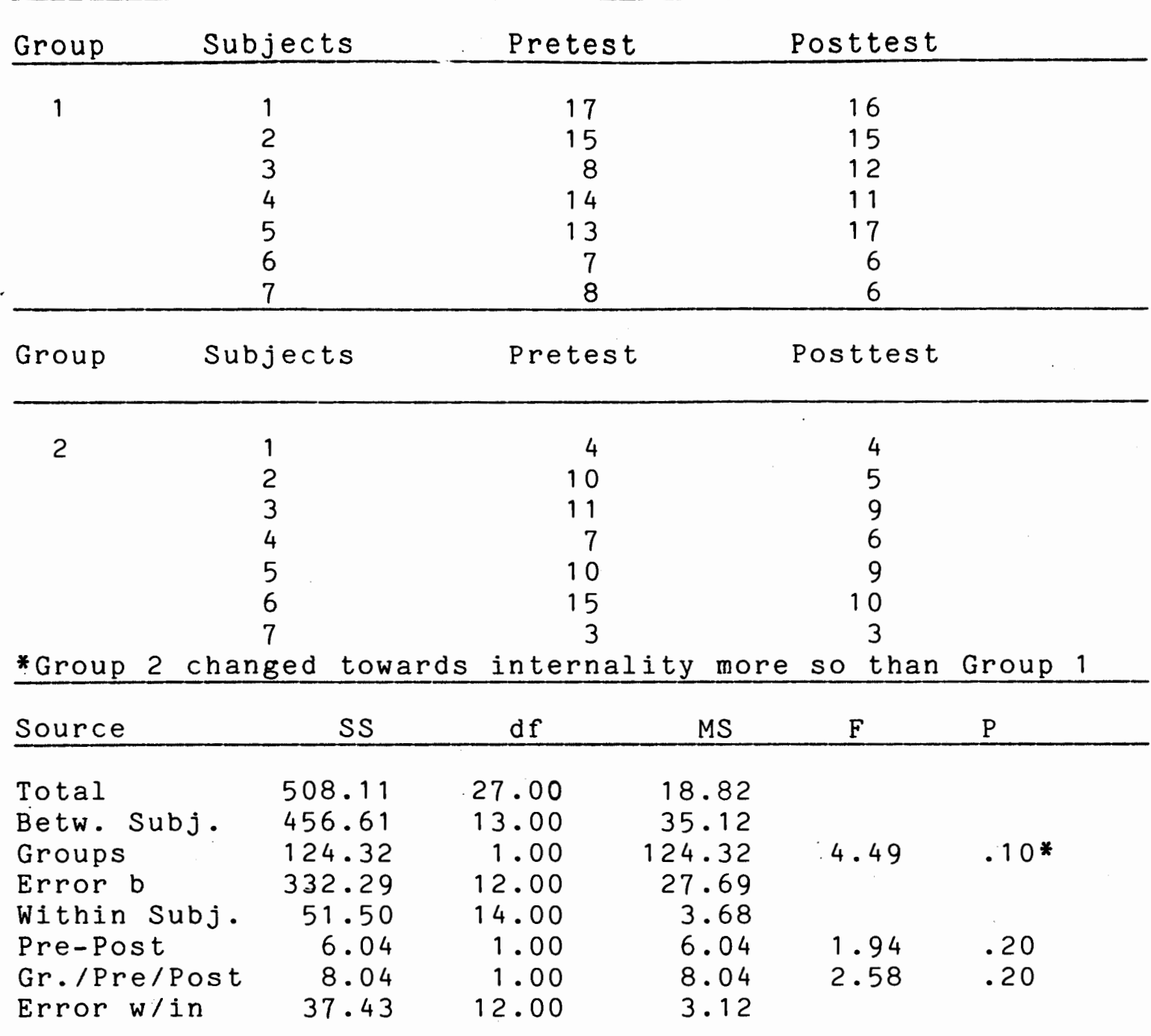

*almost to .05 level 
ANALYSIS OF VARIANCE SUMMARY TABLES

TABLE V

MANIFEST ANXIETY SCALE SCORES PRETRAINING AND POSTTRAINING

\begin{tabular}{cccc} 
Group & Subjects & Pretraining & Posttraining \\
\hline 1 & 1 & 23 & 25 \\
2 & 39 & 37 \\
3 & 11 & 14 \\
4 & 29 & 12 \\
5 & 27 & 38 \\
& 17 & 17 & 22 \\
& 18 & 9 & 9 \\
\hline
\end{tabular}

Group

Pretraining

Posttraining

\begin{tabular}{|c|c|c|c|c|c|}
\hline 2 & $\begin{array}{l}1 \\
2 \\
3 \\
4 \\
5 \\
6 \\
7 \\
\end{array}$ & $\begin{array}{r}12 \\
9 \\
15 \\
14 \\
27 \\
42 \\
17 \\
\end{array}$ & & $\begin{array}{l}12 \\
13 \\
14 \\
20 \\
21 \\
35 \\
11 \\
\end{array}$ & \\
\hline ource & SS & $d f$ & MS & $\mathrm{F}$ & $P$ \\
\hline $\begin{array}{l}\text { otal } \\
\text { etw. Subj. } \\
\text { roups } \\
\text { rror b } \\
\text { /in Subj. } \\
\text { re/Post } \\
\text { r./Pre/Post } \\
\text { rror w. }\end{array}$ & $\begin{array}{r}2682.11 \\
2328.61 \\
124.32 \\
2204.29 \\
353.50 \\
10.32 \\
0.32 \\
342.86\end{array}$ & $\begin{array}{r}27.00 \\
13.00 \\
1.00 \\
12.00 \\
14.00 \\
1.00 \\
1.00 \\
12.00\end{array}$ & $\begin{array}{r}99.34 \\
179.12 \\
124.32 \\
183.69 \\
25.25 \\
10.32 \\
0.32 \\
28.57\end{array}$ & $\begin{array}{l}0.36 \\
0.01\end{array}$ & $\begin{array}{l}\text { NS } \\
\text { NS }\end{array}$ \\
\hline
\end{tabular}

